\title{
REKA CIPTA PERHIASAN TARI SRIMPI PAKU ALAM IV YOGYAKARTA
}

\author{
Yulriawan Dafri \\ Alvi Lufiani *)
}

\begin{abstract}
One of the valuable heritages preserved until today within Pakualaman is the art and culture. One of the various arts and cultural heritages is Srimpi dance. There are some fundamental things on why the research / creation of Srimpi dance becomes interesting to do, besides having the purpose to reveal the existence of Srimpi dance with all the accompanying attributes, including various attributes of jewelry through the study of visual data of Wedana Renggan in the manuscript source of Langen Wibawa. The forms of jewelry that are used in the Srimpi dance during the Paku Alam IV is also expected to be clearly visualized, so that ultimately the existence of jewelry as a complementary attribute in the Srimpi dance performances will enrich arts and culture in strengthening the national identity in the eyes of the international world.

Through a review of this manuscript, ten sets of jewelry with deferent designs of Srimpi dance especially during Paku Alam IV have been created. Thus, other forms of creative and innovative jewelry designs and products based on the philosophy prevailing in the Pakualaman environment are created.

At least there are two approaches used in this research / creation, namely the approach to art history and aesthetics. In addition, semiotic analysis is also included. Exploration and experimental methods are used when making the design process. The analysis carried out does not look at the process of cause and effect, but more emphasizes on how to visually express the forms of jewelry that wants to be created. Therefore, this study uses a multidisciplinary approach.
\end{abstract}

Keywords: Langen Wibawa, Wedana Renggan, Jewelry, Srimpi Dance, Paku Alam IV.

\section{ABSTRAK}

Salah satu warisan berharga yang terdapat di lingkungan Pakualaman dan masih terus dilestarikan sampai saat ini adalah seni dan budayanya. Dari berbagai peninggalan seni dan budaya tersebut, salah satunya adalah tari Srimpi. Ada beberapa hal yang mendasar kenapa penelitian/penciptaan tari Srimpi menarik untuk dilakukan, selain memiliki tujuan untuk mengungkapkan keberadaan tari Srimpi dengan segala atribut yang menyertainya, termasuk berbagai atribut perhiasan melalui kajian data visual Wedana Renggan dalam sumber naskah kuno Langen Wibawa. Diharapkan juga akan dapat divisualisasikan secara jelas bentukbentuk perhiasan yang digunakan dalam tarian Srimpi pada masa Paku Alam IV, sehingga pada akhirnya keberadaan perhiasan sebagai atribut pelengkap dalam pertunjukan tari Srimpi ini akan memperkaya khasanah seni dan budaya dalam memperkuat jati diri bangsa dimata internasional.

* Yulriawan Dafri (yoel_dafri@yahoo.com) dan Alvi Lufiani Staf Pengajar Program studi Kriya Seni, Jurusan Kriya, Fakultas Seni Rupa, Institut Seni Indonesia Yogyakarta. 
Melalui kajian naskah kuno ini telah diciptakan 10 set perhiasan tari Srimpi dengan desain yang berbeda khususnya pada masa Paku Alam IV, dengan demikian terciptalah bentukbentuk desain dan penciptaan perhiasan yang kreatif dan inovatif berdasarkan filosofi dan 'pakem' yang berlaku di lingkungan Pakualaman.

Sedikitnya ada dua pendekatan yang digunakan dalam penelitian ini, yakni pendekatan sejarah seni dan estetika, selain itu disertakan pula analisis semiotika. Metode penciptaan eksplorasi dan eksperimen digunakan ketika proses pembuatan desain dilakukan. Analisis yang dilakukan tidak melihat pada proses sebab akibat, tetapi lebih ditekankan pada bagaimana mengungkapkan secara visual bentuk-bentuk perhiasan yang ingin diciptakan. Oleh karena itu penelitian ini menggunakan pendekatan multidisiplin.

Kata Kunci: Langen Wibawa, Wedana Renggan, Perhiasan, Tari Srimpi, dan Paku Alam IV.

\section{PENDAHULUAN}

Dalam sebuah pertunjukan Tari Srimpi, ada berbagai macam atribut dan perlengkapan yang harus disertakan untuk mendukung sebuah pertunjukan tari secara maksimal. Perlengkapan dan berbagai macam atribut tersebut menjadi bagian yang tidak bisa dipisahkan dan menjadi bagian penting yang harus tampil bersama para penarinya. Alasannya di samping berperan dalam memenuhi penampilan sebuah pertunjukan secara maksimal, ternyata atribut itu memiliki nilai simbolis dan filosofis tertentu, yang menjadi sangat sakral ketika pertunjukan tersebut berlangsung. Salah satu dari atribut dan perlengkapaan yang harus disertakan itu adalah perhiasan.

Perhiasan adalah salah satu dari benda budaya yang cukup populer dan sering menjadi bagian yang tidak dapat dipisahkan dari kehidupan wanita. Perhiasan selain memberikan nilai keindahan, juga kadang memiliki nilai filosofi dan simbolik bagi pemiliknya. Selain itu, perhiasan juga bisa memberikan sugesti tertentu dalam mempengaruhi psikologis seseorang. Apalagi bila dikaitkan dengan keberadaan perhiasan pada pertunjukan tari Srimpi di lingkungan istana kerajaan, yakni di lingkungan Pakualaman Yogyakarta, tentu menjadi sangat istimewa. Perhiasan yang terdapat pada masa Paku Alam IV merupakan salah satu warisan budaya yang harus dijaga kelestariannya dan perlu dikembangkan menjadi lebih baik, disesuaikan dengan pandangan dan kemajuan zaman yang semakin berkembang.

Konsep-konsep pemikiran budaya Jawa yang penuh dengan simbol-simbol tertentu masih dapat dilihat dari perhiasan yang diciptakan. Perhiasan yang terdapat dan berkembang di masa Paku Alam IV mencerminkan seni dan budaya adiluhung yang diwariskan oleh kerajaan dan keluarga bangsawan, serta perlu diingat bahwa seni budaya yang dikembangkan merupakan kebudayaan yang telah ada dan berlangsung secara turun temurun. $\mathrm{Hal}$ ini juga berlaku terhadap pemakaian perhiasan dan motif hias yang khusus dipakai dalam tarian Srimpi di lingkungan Pakualaman. Namun pada kenyataannya bentuk perhiasan yang terdapat pada tari Srimpi khususnya di masa Paku Alam IV belum diketahui secara pasti, karena tidak ada data dan informasi yang menerangkan secara jelas tentang bentuk perhiasan tari Srimpi yang pernah dibuat pada masa itu. Informasi yang didapat hanyalah cerita tentang tari Srimpi pada Paku Alam IV secara umum. Dikatakan bahwa tari Srimpi memang ada pada masa Paku Alam IV, tetapi tidak pernah terekspose secara jelas 
dan detil seperti pada masa-masa Paku Alam sebelum dan sesudahnya. Bukti-bukti fisik (artifak) perhiasan tari Srimpi yang ditingalkan hampir dipastikan tidak ada, atau tidak terdeteksi sama sekali (wawancara dengan nara sumber R.M. Murhadi).

Berdasarkan kondisi ini, maka dipandang perlu diadakan pengkajian secara mendalam serta rinci melalui berbagai metode pendekatan dan menelusuri sumber lisan maupun tulisan. Salah satu referensi yang dapat dipercaya kebenarannya adalah dengan menelaah naskah kuno Langen Wibawa. Naskah ini memuat uraian pertunjukan tari yang diungkapkan melalui teks berupa tulisan dan teks berupa gambar. Gambar berjenis wedana dengan pola wedana renggan dan wedana gapura renggan tidak hanya sekedar memberikan nilai estetika pada naskah, tetapi juga mempunyai makna tertentu. (Naskah Langen Wibawa, kode koleksi 0124/PP/73-LI.20). Oleh karena itu, pesan yang disampaikan melalui teks berupa visual gambar harus diketahui, dan usaha untuk mengetahui bentuk perhiasan tari Srimpi pada masa Paku Alam IV melalui interpretasi gambar mutlak diperlukan.

Harapannya adalah bentuk perhiasan tari Srimpi pada masa Paku Alam IV dapat diidentifikasi dan direka ulang untuk mencari bentuk yang sebenarnya, yang pada akhirnya keberadaan perhiasan pada tari Srimpi tersebut tetap dapat tampil dan dikenal sebagai salah satu artifak yang adiluhung dan tetap eksis mengikuti perubahan zaman.

Penciptaan perhiasan tari Srimpi dikembangkan sesuai dengan konsep baru, tetapi tidak mengubah makna dan mental template dari budaya lokal yang dimiliki oleh lingkungan Pakualaman. Muatan lokal atau local genius harus tetap disertakan dalam mewujudkan perhiasan ini. Perhiasan yang diciptakan harus tetap mengandung roh dan spirit yang sudah menjadi pakem dan berlaku di lingkungan Pakualaman, khususnya pada masa Paku Alam IV.

\section{PEMBAHASAN}

Penciptaan desain - desain perhiasan tari Srimpi belum atau tidak pernah dilakukan sebelumnya oleh peneliti atau perancang manapun. Untuk menunjang penelitian /penciptaan ini dibutuhkan berbagai pustaka sebagai sumber terkait dengan tema yang dipilih, yaitu Reka Cipta Perhiasan tari Srimpi Paku Alam IV. Tidak banyak buku yang membicarakan khusus tentang koleksi bersejarah Pakualaman yang beredar di pasaran. Namun demikian data-data tentang tari Srimpi beserta perhiasan pendukungnya hanya dapat ditemukan dalam buku-buku tentang tarian Jawa.

Dari naskah-naskah katalog perpustakaan Puro Pakualaman, salah satu naskah yang banyak menceritakan tentang keberadaan tari Srimpi dengan segala atribut yang menyertainya adalah naskah Langen Wibawa. Naskah ini berasal dari pemerintahan K.G.P.A.A Paku Alam IV (1864-1878). Naskah ini menggunakan bahasa Jawa dan menceritakan sekumpulan lagon sebagai salah satu aspek musik tari. Selain itu dalam Langen Wibawa ini, terdapat Wedana Renggan atau tulisan berbingkai gambar-gambar indah yang memiliki nilai filosofi dan makna simbolik tertentu. Dari data visual gambar-gambar tersebut menjadi pedoman untuk mengidentifikasi bentuk perhiasan yang ada dalam tarian Srimpi masa itu.

Untuk melacak keberadaan perhiasan pada tari Srimpi di lingkungan Pakualaman, khususnya pada masa Paku Alam IV dengan segala aspek yang terkait dengannya, maka diterapkan penelitian kualitatif dengan menggunakan pendekatan multidisiplin. Dalam 
pembahasan, penelusuran, dan pelacakan perhiasan tersebut, paling tidak akan digunakan pendekatan sejarah dan estetika serta akan dibantu dengan analisis semiotika. Seperti apa yang dikatakan oleh Soedarsono, bahwa metode penelitian seni rupa (perhiasan) dapat didekati dengan ilmu komunikasi, antropologi, arkeologis, sosiologis, historis, metalurgis, psikologis, dan ikonografis. Pendekatan multidisiplin jelas sangat dimungkinkan, bahkan dianjurkan dan seni rupa lebih disarankan menggunakan penelitian kualitatif. (Soedarsono, 2001:194)

Analisis yang dilakukan tidak melihat pada proses dari sebuah sebab akibat, tetapi ditekankan bagaimana mengungkapkan secara tekstual dan kontekstual terhadap perhiasan yang ditemukan. Selain itu dalam proses pembuatan perhiasan tersebut juga akan digunakan paling sedikit dua metode penciptaan yakni metode eksplorasi, dan eksperimen, serta dilengkapi dengan proses perwujudan.

R.M. Soedarsono, dalam salah satu bukunya mengupas tentang tari Srimpi lengkap dengan fiosofi atau kisah dibaliknya. Dijelaskan juga tentang makna simbolis dari tari Srimpi oleh pakar tari dari Kraton dan perbedaan tari Srimpi kraton Yogyakarta dan Surakarta. Dalam kesempatan lain beliau juga membicarakan cukup detil tentang tata busana sang penari, yang mana diketahui bahwa tata busana merupakan salah satu hal penting selain perhiasan yang dikenakan oleh para penari. Macammacam perhiasan yang biasanya dikenakan misalnya jamang (hiasan kepala), garuda mungkur, sumping, kelatbau, subang, pending, kalung dan lain sebagainya.( R.M. Soedarsono, 1997: 291-300)

Banyak orang beranggapan bahwa perhiasan sering dianggap semata-mata hanya sebagai pelengkap penampilan seseorang. Kenyataannya tidaklah demikian, karena sesungguhnya perhiasan merupakan sebuah benda yang bermakna (Helen, 1995: 24), apalagi perhiasan yang khusus diciptakan untuk kebutuhan keluarga kerajaan. Karena dalam setiap pembuatannya perajin atau empu perhiasan selalu mempunyai berbagai pertimbangan, baik secara estetik maupun simbolik. Jadi dapat dikatakan bahwa perhiasan yang dikenakan tidak hanya indah secara visual, melainkan juga bermakna filosofi.

Makna dan fungsi dalam pemakaian busana dan pelengkapnya, termasuk dalam hal ini perhiasan yang biasa dikenakan oleh para raja, permaisuri, penari, dan anggota kerajaan lainnya memiliki simbol dan mengikuti tata cara yang baku dalam pemakaiannya (Mari S. Condronegoro, 1995: 17-38). Sama halnya dengan motif batik dengan muatan nilainilai filosofis berdasarkan motif, bentuk dan warnanya, juga tentang fungsi busana (kostum) dan perhiasan yang dikenakan para penari Pura Pakualaman. Diketahui bahwa seorang penari Bedhoyo dan Srimpi dirias dan diberi pakaian serta perhiasan yang gemerlap karena setiap kali mereka tampil bukanlah semata sebagai individu melainkan sebagai representasi atau cerminan kejayaan Kadipaten Pakualaman (Sewon Susanyo, 1993: 56). Hal ini memberikan gambaran bahwa banyak peninggalan budaya luhur nenek moyang dalam berkesenian memberikan pembelajaran berharga bagi generasi berikutnya.

Pemakaian perhiasan yang sesuai dengan filosofi dan memuat pesan tertentu ternyata dapat juga dilihat pada perhiasan yang dikenakan oleh penari-penari Srimpi ketika mereka tampil dalam sebuah pementasan tari.

Seperti yang sudah diketahui bahwa sangat sedikit sekali data pustaka yang membahas tentang keberadaan tari Srimpi pada masa Paku Alam IV. Hanya saja 
dari beberapa buku atau naskah kuno seperti Langen Wibawa dalam Wedana Renggan tari Srimpi itu divisualisasikan dengan Wedana Renggan Sujalma Sari Makara Uneng. Gambar tersebut membingkai teks tentang gemulai para penari yang membuat kasmaran para penontonnya. Uniknya, di dalam teks itu juga disebutkan, bahwa para penari Srimpi tersebut berasal dari gunung. Tampaknya, pada masa Paku Alam IV ini ada satu tradisi memboyong perempuan desa/gunung ke Istana. Para perempuan desa tersebut kemudian dididik ala Kraton sampai menjadi penari yang handal dan dikagumi oleh para penonton.

Langkah lain yang dilakukan peneliti adalah melihat referensi yang ada, seperti menyaksikan langsung pergelaran tari Srimpi yang diselenggarakan di Pura Pakualaman, dan memperbandingkannya dengan tari Srimpi yang ada di Kraton Yogyakarta serta Kraton Surakarta. Dari hasil pengamatan, diyakini bahwa gerak maupun aksesoris pendukung yang dikenakan para penari Srimpi Paku Alam lebih mengarah ke gaya Kraton Surakarta dan berbeda dengan gaya Yogyakarta.

\section{Awal tari Srimpi diperkenalkan}

Pada awalnya tari Srimpi hanya ditarikan oleh gadis-gadis keturunan bangsawan. Tetapi sejak tahun 1918, ketika sebuah sekolah tari dari perkumpulan krida Beksa Wirama didirikan di Yogyakarta dibawah pimpinan putera Sultan, tari Srimpi diajarkan kepada semua perempuan yang bersekolah di tempat tersebut. (Claire Holt, 1967: 148), baru beberapa masa kemudian tari ini mulai banyak diminati oleh remaja-remaja di lingkungan kerajaan.

Menurut bapak R.M. Murhadi, seorang narasumber dan budayawan dari Pura Pakualaman menjelaskan, bahwa tari Srimpi itu pada dasarnya berisi ajaran yang mengingatkan manusia akan asas ketuhanan. Berasal dari kata Sri yang berarti indah, cahaya, nur, serta impi yang berarti dalam tidur. Pengertian harafiah dari Srimpi adalah "kehidupan manusia yang gemerlap itu hanya bagaikan sebuah mimpi yang bersifat sementara', sehingga kita harus selalu ingat pada Tuhan yang Maha Abadi. Segala filosofi ketuhanan tersebut diekspresikan dalam bentuk tari Srimpi. Simbolisasi tarian Srimpi yang berjumlah empat orang itu juga mempunyai makna khusus, yakni

1. Kehidupan manusia itu harus mematuhi tatanan dari Sang Maha Pencipta

2. Manusia harus tahu jalan menuju Sang Penata, seperti mampu menahan nafsu dan bersabar

3. Manusia mampu hidup dalam tatanan yang baik

4. Manusia harus mengenal Sang Maha Pencipta

Dari situ dapat dikatakan bahwa tari Srimpi bukan hanya semata sebuah karya seni tari, atau pertunjukan, melainkan juga merupakan simbol pengingat akan keberadaan Tuhan. Tari Srimpi itu sendiri mempunyai beberapa jenis, tetapi intinya tetap bernilai ketuhanan.

Pada pertunjukan Gelar Budaya yang diselenggarakan oleh Pura Pakualaman berkolaborasi dengan Kraton Yogyakarta beberapa waktu silam, diperagakan juga tari Srimpi dari Pura Pakualaman. Dari pertunjukan tersebut didapat poin-poin penting yang dapat dipakai sebagai landasan penciptaan, seperti warna, bentuk serta ornamen-ornamen visual yang dikenakan oleh para penari Srimpi, termasuk di dalamnya perhiasan-perhiasan yang melekat pada para penari tersebut. Selain sumber yang telah disebutkan diatas, sumber lain yang dijadikan sebagai pijakan adalah keterangan nara sumber terpercaya dari Pura Pakualaman, budayawan maupun ahli tentang budaya dan sastra Jawa dari Universitas Gadjah 
Mada Yogyakarta. Pengidentifikasian perhiasan tari Srimpi juga dilakukan dengan melihat secara langsung perhiasan yang dipakai oleh para penari serta mencoba untuk merekonstruksinya kembali.

Dari hasil rekonstruksi tersebut didapat berbagai macam alternative desain perhiasan tari Srimpi yang ide dan bentuk dasarnya mengacu pada bentuk yang sudah ada. Berdasarkan data visual yang terdapat pada Naskah Langen Wibawa dengan Wedana Renggan di dalamnya, dapat disimpulkan bahwa ornamen yang dipakai pada era Paku Alam IV lebih banyak yang mengacu pada motif flora dari pada fauna. Namun, ada satu motif fauna yang cukup menonjol terlihat disini, yaitu motif kupu-kupu. Motif kupu-kupu itulah yang kemudian diolah dan dijadikan sebagai sebuah ikon utama dari perhiasanperhiasan yang dikenakan oleh para penari Srimpi.

Selain itu data lain yang memperkuat hal tersebut berasal dari cerita bahwa gambar kupu-kupu di bagian latar Wedana Renggan diidentikkan dengan kisah perempuan gunung yang menjadi putri istana. Antara kupu-kupu dan para perempuan penari tersebut sama-sama telah mengalami 'metamorfosa', sehingga mengubah segalanya, termasuk perilakunya dalam kehidupan di lingkungan Pakualaman.

\section{Kegiatan yang telah dilaksanakan}

Berbagai alternatif desain yang telah dihasilkan dalam penelitian ini adalah desain perhiasan jamang, sumping, kelatbau, slepe/pendhing, cunduk menthul, kalung dan gelang. Masing-masing perhiasan tersebut dibuat dalam bentuk set. Satu set perhiasan dibuat dalam 5-6 item perhiasan. Masing-masing set perhiasan tersebut mempunyai perbedaan atara satu dengan lainnya. Hal ini bertujuan untuk memberikan berbagai variasi dari perhiasan tari Srimpi berdasarkan interpretasi data visual yang terdapat dari naskah Langen Wibawa maupun dari pengamatan terhadap pertunjukan tari Srimpi yang selama ini pernah ada, baik yang berasal dari Pura Pakualaman maupun dari Kraton Yogyakarta. Adapun beberapa aktifitas yang telah dilaksanakan adalah sebagai berikut.

1. Menginterpretasikan gambar yang ada pada Wedana Renggan dalam naskah Langen Wibawa ke dalam bentuk desain perhiasan tari Srimpi

2. Menuangkan ide dasar perhiasan tari Srimpi yang selama ini sudah dikenakan oleh para penari Srimpi ke dalam sebuah desain baru dengan tetap mengacu pada pakem yang ada

3. Menciptakan 10 jenis perhiasan tari Srimpi dengan menggunakan ornamen dan motif hias yang ada dalam Wedana Renggan

4. Kesepuluh perhiasan yang telah diciptakan tersebut adalah: Chunduk Mentul, Jamang, Kelatbau, Kalung susun tiga, Pending, Gelang, Giwang, Cincin, Gurdho, dan Sumping

\section{Hasil Reka Cipta Perhiasan}

Dalam penelitian ini telah diciptakan beberapa desain perhiasan dan mewujudkan 10 jenis perhiasan tari Srimpi. Dalam proses eksekusinya ternyata diperlukan ketelitian dan kepekaan dalam mengidentifikasi data visual yang bersumber dari naskah kuno Wedana Renggan. Dalam proses pembuatan desain, tidak saja berpedoman pada bentuk visual dari temuan data yang ada, melainkan juga haruslah mempertimbangkan informasi teks yang terdapat dalam naskah tersebut guna mempertegas keberadaan tari Srimpi di lingkungan Pakualaman. Ranah teks dipakai sebagai bahan pertimbangan dalam penentuan jenis, bagaimana bentuk 
produk desain perhiasan tersebut harus dibuat serta pemahaman terhadap makna simboliknya. Berikut ini hanya ditampilkan tiga desain perhiasan yang terpilih dan delapan produk perhiasan tari Srimpi yang telah diwujudkan.

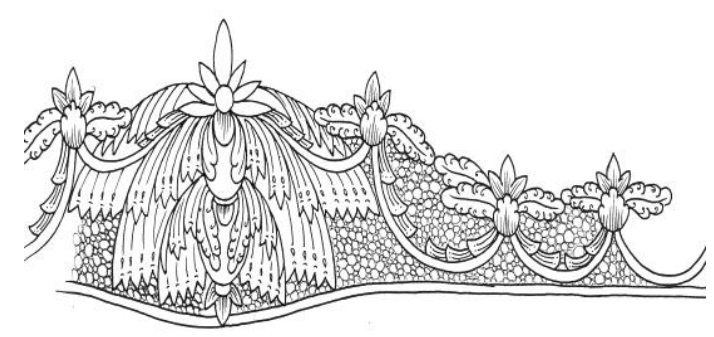

Gambar 1. Desain Jamang

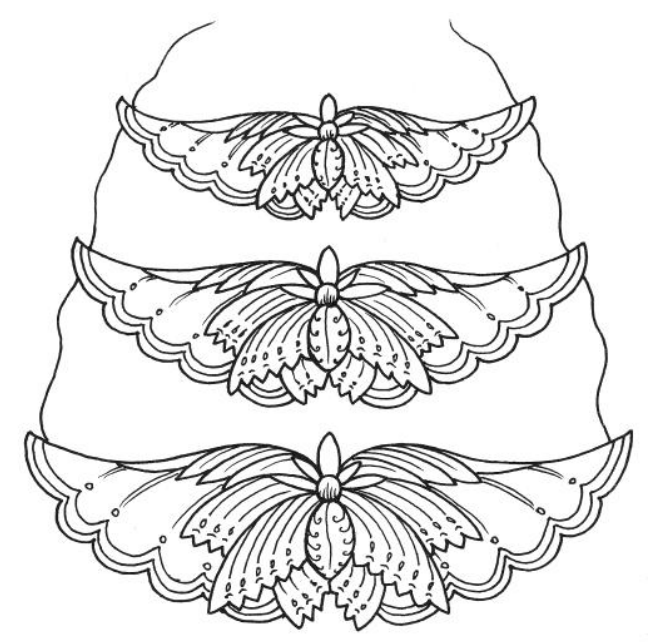

Gambar 2. Desain Kalung Susun Tiga, isian ornamennya mengambil unsur kupu-kupu

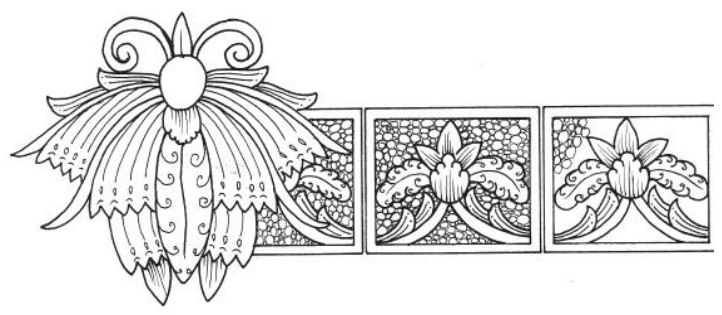

Gambar 3. Desain Pendhing, dengan latar belakang motif flora dan figur kupu-kupu.
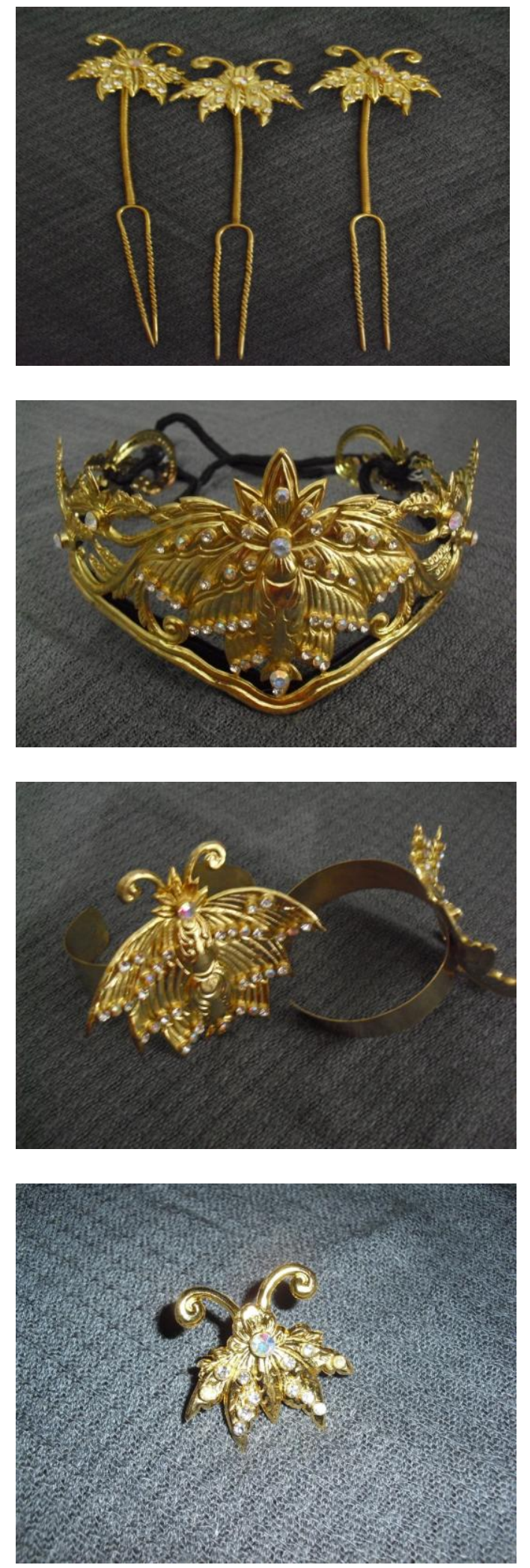

Gambar 4. Produk jadi perhiasan yang telah diwujudkan. Keterangan gambar dari kiri: cundhuk mentul, jamang, kelat bau, giwang, gurdho, dan sumping. 

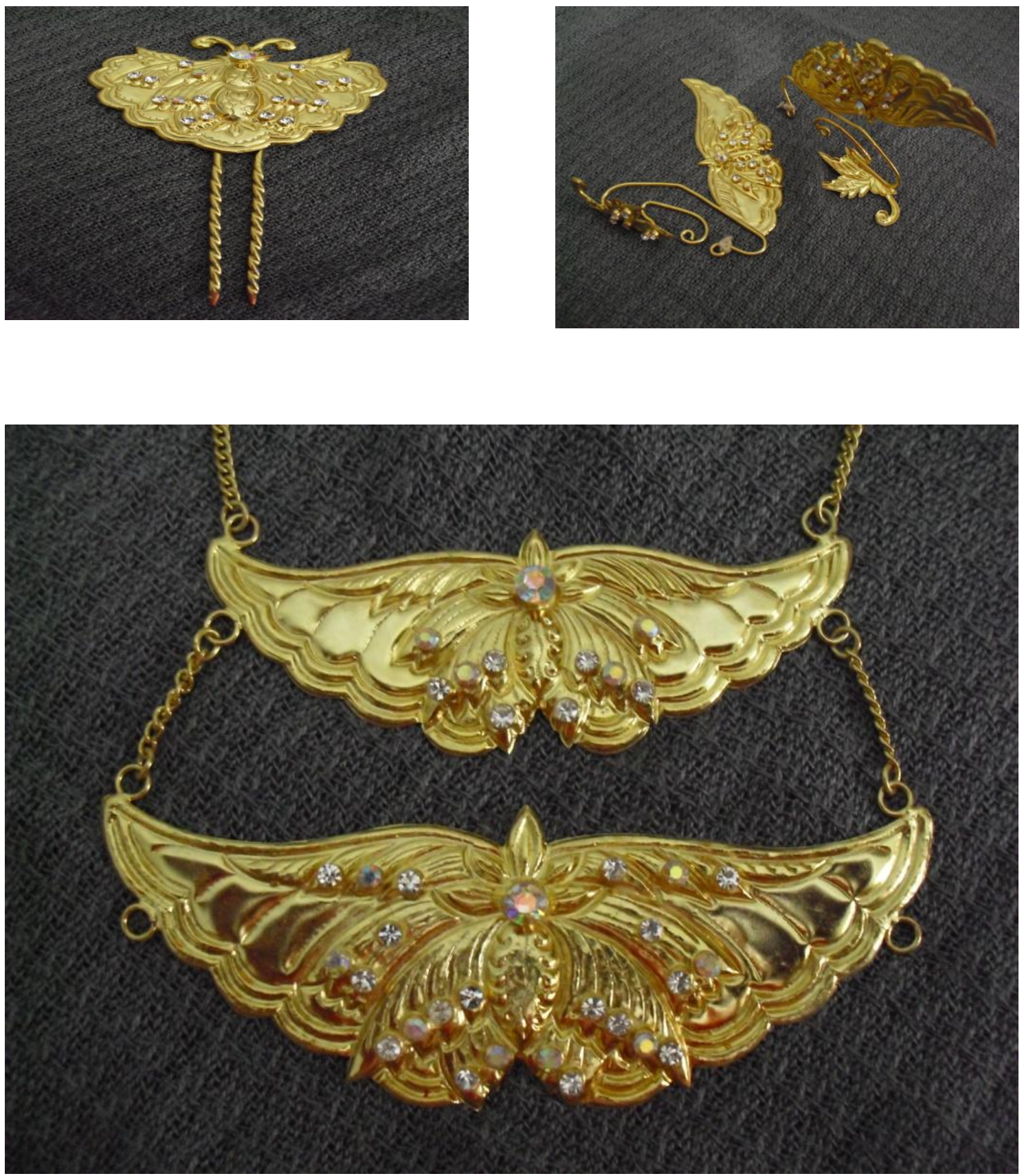

Gambar 5. Produk perhiasan kalung susun tiga 


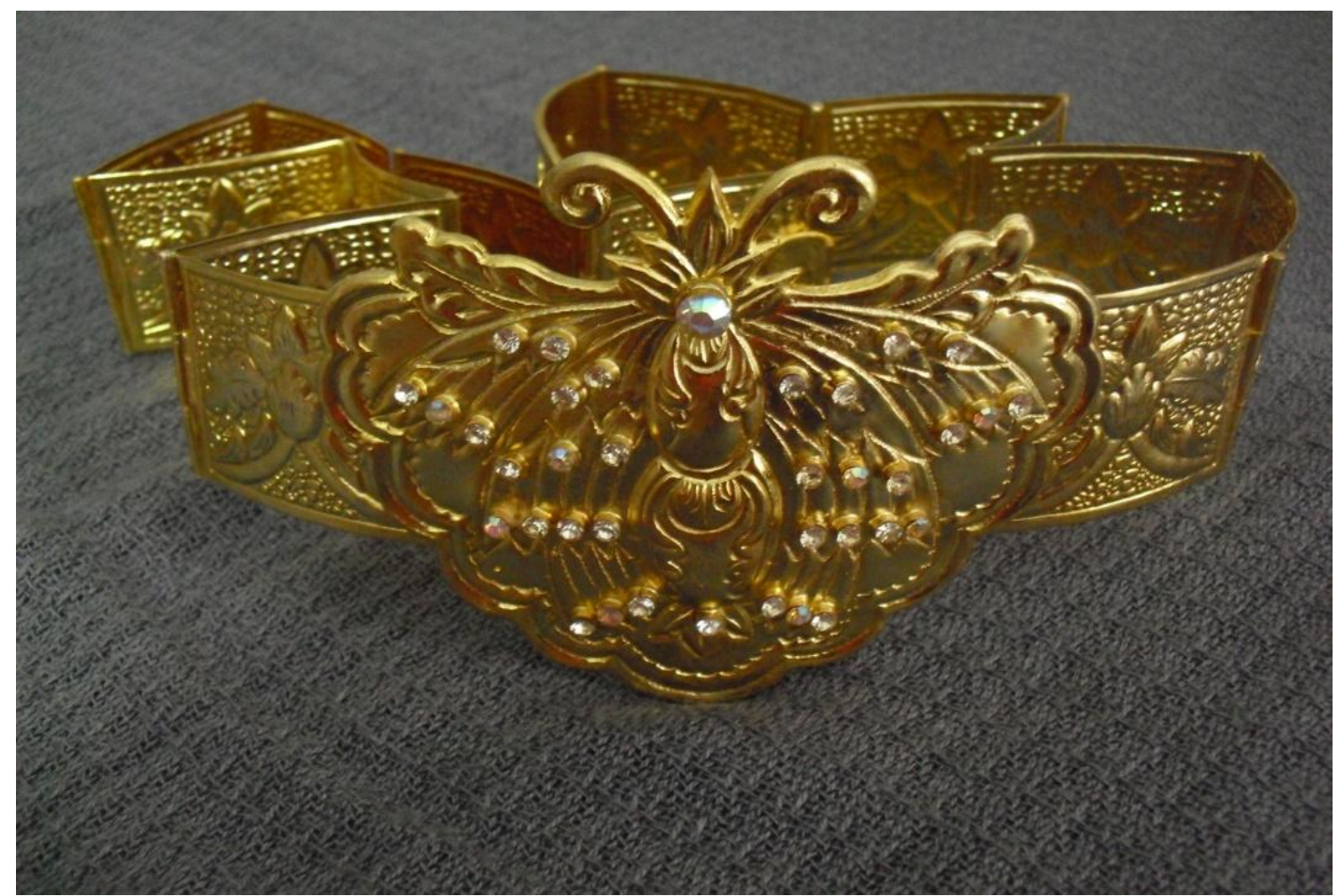

Gambar 6. Produk jadi perhiasan Pending

\section{PENUTUP}

Tari Srimpi dengan segala atribut yang melekat padanya, termasuk di dalamnya perhiasan yang dikenakan oleh para penari, merupakan salah satu warisan budaya yang seharusnya dapat dipelihara dan dijaga kelestariannya, agar tidak hilang ditelan waktu, apalagi tarian tersebut terdapat di lingkungan kerajaan. Sebagaimana diketahui bahwa tari Srimpi dan perhiasannya merupakan bagian yang tidak bisa dipisahkan dalam sebuah pertunjukan tari, namun kenyataanya artifak perhiasan tari Srimpi yang terdapat pada masa Paku Alam IV tidak pernah diketahui secara pasti wujud dan bentuknya. Tidak ada catatan penting yang khusus membahas keberadaan perhiasan tersebut. Hanya saja ada sebuah naskah kuno yakni Wedana Renggan yang menceritakan tentang keberadaan tari- tarian yang ada di lingkungan Pakualaman, dan dari naskah kuno itu didapat data visual yang digunakan sebagai acuan dalam merancang beberapa desain perhiasan tari Srimpi dan mewujudkan produk perhiasannya tersebut.

Disadari bahwa sumber data yang dipakai untuk menelaah bentuk perhiasan tari Srimpi ini sangat sedikit, untuk itu diharapkan akan ada penelitian lebih lanjut dan mendalam terhadap keberadaan perhiasan tari Srimpi pada masa Paku Alam IV.

Dari penciptaan dan perwujudan perhiasan ini diharapkan akan dapat memberikan gambaran tentang keberadaan perhiasan khusus tari Srimpi di lingkungan Pakualaman, sehingga produk tersebut dapat dipakai dalam pertunjukan tari Srimpi di lingkungan tersebut dan juga akan menjadi artifak perhiasan yang dapat 
disimpan sebagai produk budaya material bagi Puro Pakualaman.

\section{KEPUSTAKAAN}

Condronegoro, Mari S, 1995, Busana Adat Kraton Yogyakarta: Makna dan Fungsi dalam Berbagai Upacara, Yogyakarta, Yayasan Pustaka Nusatama

Drutt, Helen William, 1995, Jewelry of Our Time, New York, Rizolli International Publication, Inc.

Holt, Claire, 2000, Melacak Jejak Perkembangan Seni di Indonesia, Bandung, arti.line.

Kusmayati, A.M. Hermien, 1988, "Bedhaya di Pura Pakualaman: Pembentukan dan Perkembangannya 10901987", Tesis Pascasarjana Universitas Gadjah Mada.

Paku Alam IV,Naskah-Naskah Katalog Perpustakaan Pura Pakualaman (Paku Alam IV bertahta 18641878). Penulis kedua sampai keempat tidak mencamtumkan tarikh penulisan, tetapi menyebut nama raja pemrakarsa tarinya, yaitu Harya Prabu Suryadilaga (Paku Alam V yang bertahta pada tahun 1878-1900).

Soedarsono, R.M., 1999, Metodologi Penelitian Seni Pertunjukan dan Seni Rupa, Bandung, MSPI

\begin{tabular}{ccc} 
& ,1999, & Seni \\
\hline $\begin{array}{l}\text { Pertunjukan } \\
\text { Indonesia }\end{array}$ & dan \\
Pariwisata, Bandung, MSPI &
\end{tabular}
, 1997, Wayang Wong Drama Tari Ritual Kenegaraan di Kraton Yogyakarta, Yogyakarta, Gadjah Mada University Press. 